\title{
HERRERA, LAURA E., CURVAS Y ESPEJOS. EL CARÁCTER FUNCIONAL DE LA ACTIVIDAD MONÁDICA EN G. W. LEIBNIZ, GRANADA, EDITORIAL COMARES 2015, 230 PP.
}

\section{RESEÑA: Ricardo Rodríguez Hurtado Universidad de Granada}

Curvas y Espejos ofrece un riguroso análisis del concepto de función en la obra de Gottfried Wilhelm Leibniz. El texto de este libro se extrae de la tesis doctoral que la investigadora Laura E. Herrera realizó en la Universidad de Granada bajo la dirección del profesor Juan Antonio Nicolás Marín. El libro está publicado por la Editorial Comares en Nova Leibniz, una serie de estudios dedicados al pensamiento de este filósofo alemán, colección realizada en colaboración con el grupo de investigación Leibniz, en español.

En este estudio una conclusión se impone rápidamente sobre el resto: el concepto de función presente en la obra de G.W. Leibniz no se asimila al actual concepto matemático de función ni tampoco se reduce al concepto geométricomatemático que el propio autor elabora en sus trabajos. Aunque pueden encontrarse relaciones entre estos dos métodos de análisis matemático y el concepto de función leibniziano, es un anacronismo buscar el actual concepto matemático de función en la obra de este filósofo del siglo XVII y un reduccionismo querer otorgar a este concepto un significado únicamente geométrico-matemático dentro de sus trabajos. Laura defiende que en el 


\section{Dossiê Leibniz, Dissertatio - Volume Suplementar 03 | UFPel [2016]}

pensamiento de Leibniz encontramos una idea de funcionalidad definida por tres “elementos": legalidad, reciprocidad y serialidad. Este "carácter funcional” está presente en toda su obra, motivo por el que acuña el termino de funcionalidad expandida, también el de funcionalidad desnuda (de matematicidad). Así expresa la idea en la página 151; “A partir de allí se llegó a tres características definitorias para la función: la variación conforme a ley; la asignación recíproca entre magnitudes, que hemos denominado como correspondencia o interdependencia; y la serialidad, pues el término se usa siempre en relación con la idea de series infinitas y aplicado a términos de tales series. Hemos caracterizado estos tres elementos como los rasgos de una funcionalidad desnuda del contexto matemático en el que la hemos encontrado, o una funcionalidad expandida a otros campos".

Los principales desarrollos teóricos de esta idea de funcionalidad se identifican prestando atención a la división del libro en tres capítulos. El primer capítulo, titulado Del concepto matemático de función a la idea de funcionalidad en $G$. W. Leibniz, se centra en el análisis de la construcción matemática del concepto de función leibniziano. En él, tras analizar los diversos usos que Leibniz hace del término functio, Laura extrae de ese análisis de la construcción matemática del concepto su idea de funcionalidad expandida. El segundo capítulo, titulado La metáfora del espejo y el carácter funcional de la expresión, relaciona la idea de funcionalidad expandida con la teoría expresiva del conocimiento de Leibniz. Tras una primera discusión sobre cómo debe entenderse el carácter analógico de la relación de 
expresión para percibir su carácter funcional, Laura pasa a analizar la metáfora del espejo viviente. Esta reflexión, tan precisa en la reconstrucción lexicográfica como sugerente en la evaluación teórica, afianza y especifica la relación entre el concepto de expresión y el de función. El tercer y último capítulo, Acción y fuerza: la funcionalidad en el doble carácter de la actividad monádica, defiende que los elementos de la funcionalidad expandida se encuentran también en el aparecer fenoménico de la mónada en tanto que fuerza actuante en la naturaleza. De manera similar al segundo capítulo, en el que se establecía la determinación representativa de la mónada a través del concepto de expresión, este tercer capítulo determina la realidad efectiva de la mónada, su corporalidad fenoménica, por el concepto de fuerza activa. Estas dos formas de determinación monádica, aunque inseparables, son independientes la una de la otra. Laura expresa esta idea, en la página 208, de la siguiente manera: "No puede explicarse fenoménicamente al fenómeno en cuanto sustancia, como tampoco puede comprenderse sustancialmente a la sustancia en cuanto fenómeno; la dinámica aporta las herramientas para comprender los fenómenos dentro de su lógica y conforme a sus propias leyes. Si la acción puede manifestarse en ambos lenguajes es porque, en rigor metafísico, la fuerza es expresión y, en su manifestación fenoménica, la expresión es fuerza". Por el lado metafísico de la expresión están el carácter representativo y apetitivo de la acción; por el lado fenoménico de la fuerza, el carácter mecánico y orgánico de la misma. El último paso argumentativo es encontrar la legalidad, la reciprocidad y la serialidad de la 


\section{Dossiê Leibniz, Dissertatio - Volume Suplementar 03 | UFPel [2016]}

funcionalidad expandida en la hipótesis de la armonía preestablecida con la finalidad de relacionar estas dos dimensiones.

Las tres grandes líneas de argumentación que se acaban de exponer se defienden con un estricto rigor bibliográfico y una valiosa contextualización. Estos dos valores metodológicos son muy relevantes para comprender la profundidad filosófica y la exhaustividad académica de este estudio. Caracterizaré brevemente estas dos características.

Merece la pena mencionar los textos leibnizianos en los que Laura se apoya para defender tanto su idea de la funcionalidad expandida como las aplicaciones de esta idea a los conceptos de expresión y de fuerza. Artículos de geometría de la década de 1670 a 1680, como son Triangulum characteristica ellipsis y De functionibus plagulae quattour, y de la década de 1690 a 1700, publicados en el Acta eroditorum y el Journal de Sçavans son referencias fundamentales en el primer capítulo. También son importante algunos fragmentos de la correspondencia que Leibniz mantuvo con el matemático Bernoulli, a los cuales se les dedica un apartado. Las obras Quit sit idea (1677) y el Discours de métaphysique (1686), junto con algunas partes de la correspondencia con Antoine Arnauld (1686-1690), son referencias importantes del segundo capítulo. Sin embargo, es especialmente relevante en este capítulo el análisis bibliográfico y la reconstrucción lexicográfica que Laura hace de la metáfora del espejo viviente. Fragmentos de la correspondencia con De Volder en torno a 1700 constituyen el principal soporte bibliográfico del tercer capítulo. Aunque también son relevantes las referencias al 
Specimen dynamicum (1695), del De Ipsa Natura (1698) y del Eclairssement des difficultés que Monsieur Bayle a trouvées dans le systeme nouveau de l'union de l'ame et du corps.

El otro elemento que define la rigurosa profundidad filosófica y el excelente nivel académico de este estudio es la caracterización de los contextos polémicos a los que la obra refiere; tanto el debate científico y filosófico de la época de Leibniz como la discusión académica actual sobre la interpretación del concepto de función en la filosofía del autor alemán están muy bien retratados. La distinción entre el cálculo diferencial de Leibniz y el de fluxiones de Newton del primer capítulo es un buen ejemplo del primer nivel de contextualización. Una distinción que, además, aparece acompañada por el rastreo del origen histórico que ambos tipos de cálculo tienen en los problemas científico-geométricos de la Edad Media. También se caracterizan debates filosóficos del siglo XVII como el protagonizado por el ocasionalismo y la teoría del conocimiento de Leibniz o la discusión entre el mecanicismo y la dinámica acerca de la naturaleza del fundamento racional de la explicación científica. Cada uno de estos debates está relacionado con el principal objeto de estudio: la idea de función leibniziana.

El segundo nivel de contextualización polémica está compuesto por las diferentes posiciones que mantienen los investigadores de la filosofía de Leibniz que se han ocupado del estudio del concepto de función. Aquí encontramos los trabajos tanto de emblemáticos historiadores de la filosofía, Ernst Cassirer quizá sea el más importante dentro de este apartado, como de investigadores actuales de la filosofía de Leibniz, entre los que cabe destacar a Juan A. Nicolás o Laerke. 


\section{Dossiê Leibniz, Dissertatio - Volume Suplementar 03 | UFPel [2016]}

No obstante la cantidad de diferentes posiciones que aparecen en estos debates a lo largo de todo libro, Laura consigue expresar cada una de estas posturas con claridad y definir el detalle filosófico que diferencia su posición de la del resto de estudiosos que han investigado esta cuestión.

Una posible deficiencia de este estudio es la lectura que hace de la metáfora de las proyecciones en perspectiva. La idea de perspectiva se trata en diferentes momentos en el libro, el análisis más relevante sin embargo es el que se realiza en el capítulo segundo. En él se encuentra la discusión de Laura con Kulstad y Swoyer acerca de la forma en que interpretar el carácter funcional de la relación de expresión. En este contexto aparece la metáfora de las proyecciones geométricas en perspectiva. Al final de la discusión, en la página 166, Laura concluye: "Esto muestra también por qué el ejemplo de la perspectiva, interpretando la perspectiva en la línea matemática como proyecciones geométricas, no es un ejemplo suficiente para recoger la riqueza del concepto de expresión". Esta conclusión depende en exceso de la interpretación que sus adversarios hacen de la metáfora como función. Aunque es cierto que como defiende Swoyer, la preservación de la estructura está presente en la metáfora como elemento geométrico, aún así la conclusión sigue pareciendo bastante acelerada. Pues las proyecciones geométricas, sobre las que se realizan las construcciones en perspectiva, no son un discurso exclusivamente matemático sino que también constituyen el estudio científico de la representación. Leibniz, quien estudió algunas de las principales obras de esta disciplina en el sentido apenas expresado, 
también tiene en cuenta esto al hablar de las proyecciones geométricas en perspectiva. Las cuales no son para él un modelo exclusivamente geométrico para pensar la expresión (a través de funcionalidad; como asumen Kulstad, Swoyer y Laura), sino que también sirven para pensar la representación; las leyes constitutivas de este fenómeno gnoseológico. En este punto se le podría exigir al estudio un mayor desarrollo y puntualización, pues Laura yerra únicamente al circunscribir y aislar un sentido de perspectiva, las proyecciones geométricas, del resto de las posibles acepciones de este concepto. De la misma forma que no se puede anticipar que pueda aislarse este sentido del resto de usos que Leibniz hace de la perspectiva, tampoco puede anticiparse que la autora no pudiera hacerse cargo del resto de posibles sentidos de que Leibniz adscribe a este concepto; ésta es por lo tanto una apreciación crítica de menor calado. La investigación que se ofrece en este trabajo no pierdo por ello ni una pizca de profundidad, constituye un estudio muy recomendable para estudiosos de Leibniz y prácticamente obligatorio para aquellos que quieran estudiar el concepto de función en el sistema filosófico del autor alemán. 